\title{
The evaluation of mandibular canal visibility on cone beam computed tomography (CBCT) images: A cross-sectional study
}

\author{
Seyed Hossein Razavi ${ }^{1}$, Soudeh Berahmand ${ }^{2 *}$, Khalil Sarikhani Khorami ${ }^{1}$, Motahareh Kaboodsaz \\ Yazdi $^{1}$, Nasim Namiranian ${ }^{3}$ \\ 1. Department of Oral and Maxillofacial Radiology, School of Dentistry, Shahid Sadoughi University of Medical \\ Sciences, Yazd, Iran. \\ 2. School of Dentistry, Shahid Sadoughi University of Medical Sciences, Yazd, Iran. \\ 3. Yazd Diabetes Research Center, Shahid Sadoughi University of Medical Sciences, Yazd, Iran..
}

\section{Article Type:}

Original Article

\section{Article History:}

Received: 2 Apr 2019

Revised: 30 Jul 2019

Accepted: 2 Aug 2019

\section{*Correspondence:}

Soudeh berahmand

Student Research

Committee, School of

Dentistry, Shahid

Sadoughi University of Medical Sciences, Yazd, Iran

soudeh.b92@gmail.com

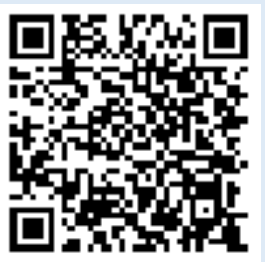

\begin{abstract}
Background and objectives: An effective factor in choosing the correct place for the dental implant and performing surgical procedures in the posterior regions of mandible is the position of the mandibular canal. Failure to consider this important landmark will damage the inferior alveolar nerve. Considering the widespread use of implants and the precision of the images obtained from CBCT. The aim of this study was to evaluate the rate of visibility of mandibular canal by $\mathrm{CBCT}$ in order to prevent damage to the inferior alveolar nerves and arteries.

Methods: In this study, 90 archived CBCT images of patients from a private center of oral and maxillofacial radiology in Yazd that was taken by technician was evaluated during 2012-2019. The visibility of the mandibular canal in reconstructed panoramic images of CBCT was assessed by a dentistry student trained by the maxillofacial radiologist in five areas in different thicknesses on each side. Data were analyzed using SPSS 17 software. Chi-square, and correlation coefficient were done.

Results: In total, in $53.38 \%$ of CBCT images both borders of mandibular canal were visible, in $17.95 \%$, only one border was visible (difficult observation) and in $28.7 \%$ of cases, lack of visibility of mandibular canal was reported. There was no significant difference between sex, age, side and thickness in mandibular canal visibility $(\mathrm{P}>0.05)$. Conclusion: In more than half of CBCT images, both borders were clearly visible in both right and left sides; therefore we can conclude that CBCT is a useful tool for the observation of mandibular canal before surgeries.
\end{abstract}

Keywords: Mandibular canal, Cone Beam Computed Tomography, Visibility, Thickness

Copyright@ 2018, Jorjani Biomedicine Journal has published this work as an open access article under the terms of the Creative Commons Attribution License (http://creativecommons.org/licenses/by-nc/4.0/) which permits noncommercial uses of the work while it is properly cited. 


\section{Introduction}

Mandibular canal is an important bony landmark located in the mandible, which the inferior alveolar nerve and vessels is passing through it. The canal extends from the mandibular foramen to the mental foramen and passes the ramus, mandibular angle and body, and carries on to the mental area in the mandible (1). It is suggested to have sufficient information on the path and the variations observed in it and topography of the canal (2).

Difficult anatomy avoids predicting the location of the inferior alveolar nerve during various surgeries (such as third molar surgeries, implant placement) and leads to several problems such as iatrogenic damage to the inferior alveolar vessels and nerve (3). The visibility of the mandibular canal relies on the bone density of its constituent walls, anatomical features of the canal and the applied technique. Thus, the invisibility of canal appears reasonably in some imaging techniques (4). Among the existing radiographic techniques to observe the canal, periapical radiographs are not adequately efficient for examining the probability of damages to the inferior alveolar nerve, which was due to the absence of reliable information (5). In panoramic images, magnification and distortion of the anatomical structure along with the superimposition of vertebral column can lead to less or more estimation than the real location and size of mandibular canal and mental foramen $(6,7)$.

CBCT, as a new technology, reduces the radiation dose, costs and time (8) and is also capable of preparing the high spatial resolution images. Moreover, it can be replaced with panoramic images in exact determining of the mandibular canal due to the ability in analyzing the images in three dimensions (9).
The location of the mandibular canal is an influential factor in the selection of the correct place of the implant in the posterior area of the mandible (10). Among the existing techniques, CBCT is a selective method and is aimed at evaluating the pre-implanting radiography (11).

With respect to the widespread prevalence of implant application and surgery in the posterior area of the mandible and the accuracy of images obtained from CBCT, this study was attempted to examine the accuracy of this radiography in determining the location and measurement of the mandibular canal in different areas of mandible and in different slice thicknesses of CBCT on each side.

\section{Materials and Methods}

The study was a cross-sectional study on 90 archived CBCT images collected from individuals referred to a private oral, maxillofacial radiology clinic in Yazd from 2012-2019, who was imaged due to implant placement. Inclusion criteria for the study were images of individuals over 18 years old without any radiolucent or radiopaque lesions in the ramus or body of mandible or bifid mandibular canal or accessory mental foramen in the image. The individuals were separated into four groups based on their age range: under 30, 30-40, 40-50, and over 50.

These images were prepared with the use of CBCT device with the commercial name "planmeca" and the model "promax" (Helsinki, Finland) with $84 \mathrm{kV}, 12 \mathrm{~mA}$, an exposure time of $13 \mathrm{~s}$, the voxel size of 160 $\mu \mathrm{m}$ and $80 \times 100 \mathrm{FOV}$.

Taken images were inserted into the computer and saved in DICOM format on a CD and were available for the observer. 
Investigating and measuring images was conducted by a dentistry student trained by the maxillofacial radiologist with the application of Planmeca Romexis Viewer 2. 9. 2. $\mathrm{R}$ in an optimum condition in terms of brightness and contrast, which was in a semidark room exhibited on a 91.6-inch laptop screen with HD resolution and 4GB of ram in similar conditions.

First, a reconstructed panoramic view of the CBCT was created by drawing the appropriate arch at the center of the buccolingual width manually in the axial view of the CBCT "figure 1".

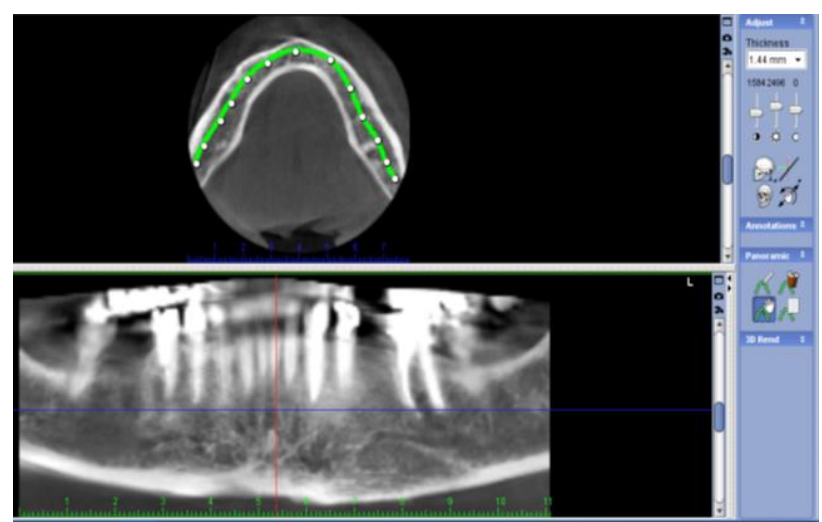

Figure1: The manner of selection of a reconstructed panoramic view

Then, the image of canal on reconstructed panoramic was divided into 5 zones from the mandibular foramen to the area of mental foramen "figure 2" (12). They were as follows:

Zone1: The initiation of mandibular canal: end of third molar

Zone2: Around the third molar: inferior than the third molar furcation

Zone3: Around second molar: inferior than the second molar furcation

Zone4: Around the first molar: inferior than the first molar furcation
Zone5: Around the second premolar or the end of canal: inferior than the apex of second premolar

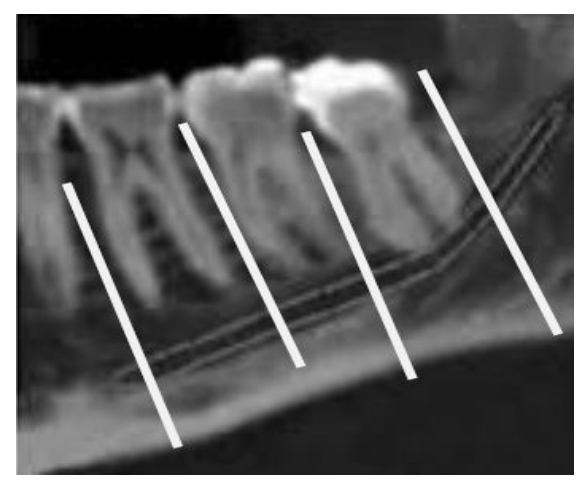

Figure2: Division of five zones on each side of the image

The required thickness were selected in the part "show viewport setting" and three thicknesses, including 0.5, 1 and $2 \mathrm{~mm}$, were investigated "figure 3".

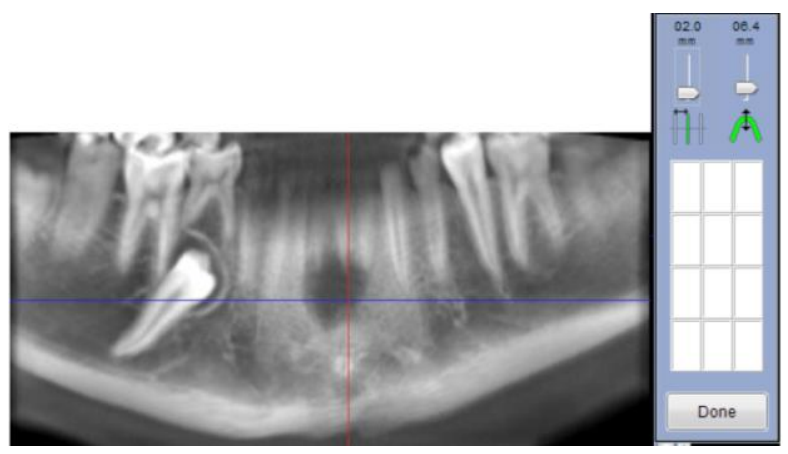

Figure3: Adjustment of the intended thickness on the reconstructed panoramic view

The researcher examined the possibility of observing the superior and inferior borders of canal in the five specified zones on both right and left sides for each patient. This was conducted in three thicknesses of $0.5,1$ and 2 $\mathrm{mm}$.

The visibility of the mandibular canal was known as observing or not observing the superior and inferior borders of canal and was indicated with + and - signs. After data 
collection, each of these zones was scored depending on visibility or invisibility (number of positive and negative cases) of canal.

Then, the collected data from the reconstructed panoramic view were recorded in the pre-prepared forms along with the age and sex of the individuals. The obtained results related to age and sex were also investigated.

The visibility of the canal was divided into three categories: clearly visible, visible with difficulty and invisibility. The first one was considered as the rate of observing both borders (score 1), the second one as observing one border (score 0.5 ) and the third one as observing no border (score 0 ). Then, the visibility was evaluated on the basis of viewing quality for each of the zones separately. Generally, the visibility average was calculated in terms of ease and difficulty of observing in each thickness $(0.5,1$ and 2 $\mathrm{mm}$ ) and in each zone (1-2-3-4-5), in order to evaluate the visibility of mandibular canal in CBCT images.
After collecting data and entering them into the computer, the results were analyzed by application of SPSS17 software, chi-square.

\section{Results}

In this study, $90 \mathrm{CBCT}$ images were studied in which $40(44.4 \%)$ of them were male and $50(55.6 \%)$ of them were female. The mean age of participants was $40.08( \pm 12.2)$ years old. The age range was 19-62. These images were investigated with the purpose of evaluating the visibility of the mandibular canal.

According to the "tables 1 and 2", with respect to the thickness of $0.5 \mathrm{~mm}$, it was reported that the highest frequency of clear visibility of the mandibular canal on right side was in zone $2(60 \%)$ and the lowest frequency was in zone $1(44.4 \%)$. Also, it was reported that the highest frequency with the same thickness on left side was in zones 2 and 3 $(55.6 \%)$ and the lowest frequency was in zone $1(48.9 \%)$.

Table 1: Frequency of mandibular canal visibility by separation of the zones at $0.5 \mathrm{~mm}$ thickness on the right side

\begin{tabular}{|c|c|c|c|c|}
\hline zone & $\begin{array}{c}\text { Lack of visibility of both } \\
\text { borders } \\
\text { Number (\%) }\end{array}$ & $\begin{array}{c}\text { Visibility of one border } \\
\text { Number (\%) }\end{array}$ & $\begin{array}{c}\text { Visibility of both } \\
\text { borders } \\
\text { Number (\%) }\end{array}$ & p-value \\
\hline 1 & $35(38.9)$ & $14(15.6)$ & $40(44.4)$ & 0.01 \\
\hline 2 & $21(23.3)$ & $15(16.7)$ & $54(60)$ & 0.091 \\
\hline 3 & $15(16.7)$ & $22(24.4)$ & $53(53.8)$ & 0.095 \\
\hline 4 & $21(23.3)$ & $20(22.2)$ & $49(54.4)$ & 0.065 \\
\hline 5 & $21(23.3)$ & $19(21.1)$ & $50(55.6)$ & 0.055 \\
\hline
\end{tabular}


Table 2. Frequency of mandibular canal visibility by separation of the zones at $0.5 \mathrm{~mm}$ thickness on the left side

\begin{tabular}{|c|c|c|c|c|}
\hline zone & $\begin{array}{c}\text { Lack of visibility of both } \\
\text { borders } \\
\text { Number (\%) }\end{array}$ & $\begin{array}{c}\text { Visibility of one border } \\
\text { Number (\%) }\end{array}$ & $\begin{array}{c}\text { Visibility of both borders } \\
\text { Number (\%) }\end{array}$ & p-value \\
\hline 1 & $33(36.7)$ & $13(14.4)$ & $44(48.9)$ & 0.023 \\
\hline 2 & $27(30)$ & $13(14.4)$ & $50(55.6)$ & 0.087 \\
\hline 3 & $22(24.4)$ & $18(20)$ & $50(55.6)$ & 0.046 \\
\hline 4 & $31(34.4)$ & $14(15.6)$ & $45(50)$ & 0.048 \\
\hline 5 & $33(36.7)$ & $12(13.3)$ & $45(50)$ & 0.011 \\
\hline
\end{tabular}

According to the "tables 3 and 4", with respect to the thickness of $1 \mathrm{~mm}$, it was reported that the highest frequency of clear visibility of the mandibular canal on right side was in zone $3(62.2 \%)$ and the lowest frequency was in zone $1(46.7 \%)$. Also, it was reported that the highest frequency with the same thickness on left side was in zones 2 and $3(54.4 \%)$ and the lowest frequency was in zone $1(50 \%)$.

Table 3: Frequency of mandibular canal visibility by separation of the zones at $1 \mathrm{~mm}$ thickness on the right side

\begin{tabular}{|c|c|c|c|c|}
\hline zone & $\begin{array}{c}\text { Lack of visibility of both borders } \\
\text { Number (\%) }\end{array}$ & $\begin{array}{c}\text { Visibility of one border } \\
\text { Number (\%) }\end{array}$ & $\begin{array}{c}\text { Visibility of both borders } \\
\text { Number (\%) }\end{array}$ & 0.032 \\
\hline 1 & $36(40)$ & $12(13.3)$ & $42(46.7)$ & 0.053 \\
\hline 2 & $20(22.2)$ & $19(21.1)$ & $51(56.7)$ & 0.015 \\
\hline 3 & $13(14.4)$ & $21(23.3)$ & $56(62.2)$ & 0.476 \\
\hline 4 & $20(22.2)$ & $21(23.3)$ & $49(54.4)$ & 0.603 \\
\hline 5 & $20(22.2)$ & $22(24.4)$ & $48(53.3)$ & \\
\hline
\end{tabular}

Table 4: Frequency of mandibular canal visibility by separation of the zones at $1 \mathrm{~mm}$ thickness on the left side

\begin{tabular}{|c|c|c|c|c|}
\hline zone & $\begin{array}{c}\text { Lack of visibility of both borders } \\
\text { Number (\%) }\end{array}$ & $\begin{array}{c}\text { Visibility of one border } \\
\text { Number (\%) }\end{array}$ & Visibility of both borders & Number (\%) \\
\hline 1 & $34(37.8)$ & $10(11.1)$ & $45(50)$ & 0.076 \\
\hline 2 & $27(30)$ & $14(15.6)$ & $49(54.4)$ & 0.03 \\
\hline 3 & $21(23.3)$ & $19(21.1)$ & $49(54.4)$ & 0.04 \\
\hline 4 & $32(32.6)$ & $10(11.1)$ & $48(53.3)$ & 0.009 \\
\hline 5 & $31(34.4)$ & $12(13.3)$ & $47(52.2)$ & 0.073 \\
\hline
\end{tabular}


According to the "tables 5 and 6", with respect to the thickness of $2 \mathrm{~mm}$, it was reported that the highest frequency of clear visibility of the mandibular canal on right side was in zone $3(63.3 \%)$ and the lowest frequency was in zone $1(42.2 \%)$. Also, it was reported that the highest frequency with the same thickness on left side was in zone 2 $(55.6 \%)$ and the lowest frequency was in zone $4(50 \%)$. Chi-square was applied in this study to compare the visibility of the canal at the thicknesses of $0.5,1$ and $2 \mathrm{~mm}$. Consequently, $47.4 \%$ of the zone $1,56.3 \%$ of the zone $2,57.8 \%$ of the zone $3,53.1 \%$ of the zone 4 and $52.2 \%$ of the zone 5 was visible clearly based on the results in general average and between three thicknesses of the mandibular canal.

In $14 \%$ of the cases in zone $1,17.7 \%$ in zone $2,22.2 \%$ in zone $3,17.92 \%$ in zone 4 , $17.93 \%$ in zone 5 only one border was visible.

In $38.3 \%$ of the cases in the zone $1,25.9 \%$ in zone $2,19.8 \%$ in zone $3,28.8 \%$ in zone 4 , $29.8 \%$ in zone 5 both borders were not visible.

Table 5. Frequency of mandibular canal visibility by separation of the zones at $2 \mathrm{~mm}$ thickness on the right side

\begin{tabular}{|c|c|c|c|c|}
\hline zone & $\begin{array}{c}\text { Lack of visibility of both borders } \\
\text { Number (\%) }\end{array}$ & $\begin{array}{c}\text { Visibility of one border } \\
\text { Number (\%) }\end{array}$ & Visibility of both borders & Number (\%) \\
\hline 1 & $37(41.1)$ & $15(16.7)$ & $38(42.2)$ & 0.058 \\
\hline 2 & $19(21.1)$ & $21(23.3)$ & $50(55.6)$ & 0.051 \\
\hline 3 & $14(15.6)$ & $19(21.1)$ & $57(63.3)$ & 0.087 \\
\hline 4 & $20(22.2)$ & $19(21.1)$ & $51(56.7)$ & 0.063 \\
\hline 5 & $22(24.4)$ & $19(21.1)$ & $49(54.4)$ & 0.065 \\
\hline
\end{tabular}

Table 6. Frequency of mandibular canal visibility by separation of the zones at $2 \mathrm{~mm}$ thickness on the left side

\begin{tabular}{|c|c|c|c|c|}
\hline zone & $\begin{array}{c}\text { Lack of visibility of both } \\
\text { borders } \\
\text { Number (\%) }\end{array}$ & $\begin{array}{c}\text { Visibility of one border } \\
\text { Number (\%) }\end{array}$ & Visibility of both borders & Number (\%) \\
\hline 1 & $32(35.6)$ & $12(13.3)$ & $46(51.1)$ & 0.061 \\
\hline 2 & $26(28.9)$ & $14(15.6)$ & $50(55.6)$ & 0.020 \\
\hline 3 & $22(24.4)$ & $21(23.3)$ & $47(52.2)$ & 0.624 \\
\hline 4 & $32(35.6)$ & $13(14.4)$ & $45(50)$ & 0.186 \\
\hline 5 & $34(38.8)$ & $13(14.4)$ & $43(47.8)$ & 0.433 \\
\hline
\end{tabular}


Totally, the frequencies of canal visibility in each five zones, in $53.38 \%$ of cases both borders of mandibular canal were visible clearly, in $17.95 \%$ of cases only one border was visible and in $28.7 \%$ of cases the mandibular canal was invisible.

There was no significant differences in the visibility of mandibular canal between the two sexes in any of the zones ( $p>0.053)$ (except zone 4 on the right side with the thickness $2 \mathrm{~mm}(\mathrm{p}=0.018)$ which was more in male than female). Also, on the basis of the results, there was no significant differences in the visibility of mandibular canal between the four age groups in any of the zones ( $p>0.063$ )

We also compared the zones 1, 2, 3, 4 and 5 at different thicknesses $(0.095<$ p-value < 0.447). In zone 1, the highest frequency was reported at thickness $1 \mathrm{~mm}$ on the right side $(46.7 \%)$ and at thickness $2 \mathrm{~mm}$ on the left side $(51.1 \%)$. In zone 2 , the highest frequency was reported at thickness $0.5 \mathrm{~mm}$ on the right side $(60 \%)$ and at thickness 2 $\mathrm{mm}$ on the left side $(55.6 \%)$. In zone 3 , the highest frequency was reported at thickness 2 $\mathrm{mm}$ on the right side $(63.3 \%)$ and at thickness $0.5 \mathrm{~mm}$ on the left side (55.6\%). In zone 4 , the highest frequency was reported at thickness $2 \mathrm{~mm}$ on the right side $(56.7 \%)$ and at thickness $1 \mathrm{~mm}$ on the left side $(53.3 \%)$. In zone 5, the highest frequency was reported at thickness $0.5 \mathrm{~mm}$ on the right side $(55.6 \%)$ and at thickness $1 \mathrm{~mm}$ on the left side $(52.2$ $\%)$.

According to the results of the chi-square, in the mandibular canal $53.3 \%$ of cases at the thickness $0.5 \mathrm{~mm}, 53.7 \%$ of them at the thickness $1 \mathrm{~mm}$ and $52.8 \%$ of them at the thickness $2 \mathrm{~mm}$ were visible clearly. Moreover, the canal was not visible in $28.7 \%$ of cases at thickness $0.5 \mathrm{~mm}, 28.8 \%$ of cases at thickness $1 \mathrm{~mm}$ and $28.6 \%$ of cases at thickness $2 \mathrm{~mm}$. In $17.7 \%$ of cases at thicknesses 0.5 and $1 \mathrm{~mm}$ and in $18.4 \%$ of cases at thickness $2 \mathrm{~mm}$ only one border was visible.

The frequencies of canal visibility on the right and left sides were compared in table 7 .

Based on the results of the chi-square, there was no significant difference in the visibility of canal between the right and left sides of the images ( $\mathrm{p}$ value $>0.057$ ). 
Table 7. Frequency of mandibular canal visibility on right and left side

\begin{tabular}{|c|c|c|c|c|c|c|c|c|c|c|}
\hline & $\begin{array}{l}\text { Right side } \\
\text { Area } 1 \\
\text { Number } \\
(\%)\end{array}$ & $\begin{array}{c}\text { left side } \\
\text { Area } 1 \\
\text { Number } \\
\quad(\%)\end{array}$ & $\begin{array}{c}\text { Right side } \\
\text { Area } 2 \\
\text { Number } \\
(\%)\end{array}$ & $\begin{array}{c}\text { left side } \\
\text { Area } 2 \\
\text { Number } \\
(\%)\end{array}$ & $\begin{array}{c}\begin{array}{c}\text { Right } \\
\text { side }\end{array} \\
\text { Area } 3 \\
\text { Number } \\
(\%)\end{array}$ & $\begin{array}{c}\text { left side } \\
\text { Area } 3 \\
\text { Number } \\
(\%)\end{array}$ & $\begin{array}{c}\begin{array}{c}\text { Right } \\
\text { side }\end{array} \\
\text { Area } 4 \\
\text { Number } \\
(\%)\end{array}$ & $\begin{array}{c}\text { left side } \\
\text { Area } 4 \\
\text { Number } \\
\quad(\%)\end{array}$ & $\begin{array}{c}\text { Right side } \\
\text { Area } 5 \\
\text { Number } \\
(\%)\end{array}$ & $\begin{array}{c}\text { left side } \\
\text { Area } 5 \\
\text { Number } \\
(\%)\end{array}$ \\
\hline $\begin{array}{l}\text { Visibility of } \\
\text { both borders }\end{array}$ & $\begin{array}{c}121 \\
(44.8)\end{array}$ & $\begin{array}{c}135 \\
(50.0)\end{array}$ & $\begin{array}{c}155 \\
(57.4)\end{array}$ & $\begin{array}{c}149 \\
(55.2)\end{array}$ & $\begin{array}{l}166 \\
(61.5)\end{array}$ & $\begin{array}{c}146 \\
(54.1)\end{array}$ & $\begin{array}{c}149 \\
(55.2)\end{array}$ & $\begin{array}{c}138 \\
(51.1)\end{array}$ & $\begin{array}{c}147 \\
(54.4)\end{array}$ & $\begin{array}{c}135 \\
(50.0)\end{array}$ \\
\hline $\begin{array}{l}\text { Visibility of } \\
\text { one border }\end{array}$ & $\begin{array}{c}41 \\
(15.2)\end{array}$ & $\begin{array}{c}36 \\
(13.3)\end{array}$ & $\begin{array}{c}55 \\
(20.4)\end{array}$ & $\begin{array}{c}41 \\
(15.2)\end{array}$ & $\begin{array}{c}62 \\
(23.0)\end{array}$ & $\begin{array}{c}59 \\
(21.8)\end{array}$ & $\begin{array}{c}60 \\
(22.2)\end{array}$ & $\begin{array}{c}37 \\
(13.7)\end{array}$ & $\begin{array}{c}60 \\
(22.2)\end{array}$ & $\begin{array}{c}37 \\
(13.7)\end{array}$ \\
\hline $\begin{array}{c}\text { Lack of } \\
\text { visibility of } \\
\text { both borders }\end{array}$ & $\begin{array}{c}108 \\
(40.0)\end{array}$ & $\begin{array}{c}99 \\
(36.7)\end{array}$ & $\begin{array}{c}60 \\
(22.2)\end{array}$ & $\begin{array}{c}80 \\
(29.6)\end{array}$ & $\begin{array}{c}42 \\
(15.5)\end{array}$ & $\begin{array}{c}65 \\
(24.1)\end{array}$ & $\begin{array}{c}61 \\
(22.6)\end{array}$ & $\begin{array}{c}95 \\
(35.2)\end{array}$ & $\begin{array}{c}63 \\
(23.3)\end{array}$ & $\begin{array}{c}98 \\
(36.3)\end{array}$ \\
\hline
\end{tabular}

\section{Discussion}

In the present study, reconstructed panoramic images of CBCT of 90 individuals were evaluated in terms of visibility of the mandibular canal in five zones of the left and right side at three thicknesses of $0.5,1$ and 2 $\mathrm{mm}$. The results obtained from CBCT images indicated that in $53.38 \%$ of cases, both borders of mandibular canal were clearly visible and in $28.7 \%$ of cases the mandibular canal was invisible. The result achieved from this study was in line with the study conducted by Olveria-Santos (4) and Miles (12).

In this study, no significant difference was reported between age, side and sex, and the visibility of mandibular canal. Whereas Mile et al. found out that age and sex had a significant effect on mandibular canal visibility. The average age was 56 years and they were grouped into four categories. But a non-linear relation was established between age and mandibular canal visibility. The reason for the difference between the present study and Mile's study was related to the different statistical populations and racial and individual differences (12).

Shokri et al did not observe a significant difference between two sexes and two sides (right and left) while evaluating the visibility of IAC (13). Similarly, there was no significant difference between two sides in the study carried out by Oliveria-Santos et al (4). Furthermore, in the study conducted by Jung et al. there was no significant difference between the two sides in the evaluation of mandibular canal visibility (14), which was in line with the results of the present study.

In the study by Singh et al. the visibility of IAC was affected by age so that the visibility of IAC became more difficult with aging (15).

Comparing the visibility of the mandibular canal in different CBCT thicknesses, there was no considerable difference between three thicknesses of $0.5,1$ and $2 \mathrm{~mm}$. This was likely due to the proximity of these three 
thicknesses, but the mandibular canal was more visible in thicknesses $2<0.5<1$, respectively.

Goodarzipoor and Arzi (2016), in their study, concluded that slice thickness had no effect on IAC visibility in cross-sectional images (16), which was in line with the results of the present study, whose visibility was compared in three thicknesses of $0.5,1$ and 2 .

Miles et al. (2015) conducted a study and investigated the IAC visibility of CBCT images of 18 years individuals and older in four zones of $\mathrm{pm} 1 / \mathrm{pm} 2 / \mathrm{m} 1 / \mathrm{m} 2$. In $56 \%$ of cases, IAC was clearly observed (12).

Shokri et al. (2014) investigated the cortication, visibility, and position of IAC in cross-sectional and reconstructed panoramic images of CBCT of 69 patients, in which IAC was visible in $89.6 \%$ of cases and also, in $56.3 \%$ of the cases, canal cortication was observed (13) that this study was in line with our study in terms of visibility of inferior and superior borders of IAC.

Moreover, Shokri et al. (13) observed the most amount of visibility in the second and third molar zones and this visibility would be decreased anteriorly on both sides. The second premolar zone had the least amount of visibility and this result was in line with our research. Also in the study by Oliveria-Santos (4), the lowest visibility was observed in the area of the mental foramen and the second premolar.

Angelopplous et al. figured out that one-third of the posterior of canal was more visible than the other parts of the canal (17).

Similar to the results of the present study and in contrast with the study by Oliveria-Santos (4), Shokri founded less visibility in the distal area of third molar compared to molar areas. The reason was that there was a submandibular fossa in the distal area of third molar, and it probably reduced the visibility of IAC due to the trabeculation and osteoporotic view (13).

Also, Suomalainen, in the use of CBCT images, realized that IAC detection and its location were likely associated with the third molar, and the complex position of the mandibular third molar make it difficult to observe the mandibular canal (18).

The advantage of this study was to investigate the visibility of mandibular canal on CBCT images in Yazd population that had not been studied before. The main disadvantage of this study is the non-generalizability of the study results, which may be due to non-random sampling. Because the study used only patient's images from a private center and therefore did not include all spectra of the population.

It is recommended for further studies to evaluate the CBCT images at higher thicknesses and at greater thickness intervals.

\section{Conclusion}

The mandibular canal on CBCT was clearly visible in more than half of the cases. This study also defined that the visibility of the mandibular canal was reduced from the posterior to the anterior areas.

Although the maximum canal visibility was recorded at a thickness of $1 \mathrm{~mm}$, no significant difference appeared between thicknesses of $0.5,1$ and $2 \mathrm{~mm}$ in terms of mandibular canal visibility. 


\section{Declarations}

The approval of the ethics committee of Shahid Sadoughi University of Medical Sciences, Yazd, IR.SSU.REC.1397.007 was obtained for this research.

\section{Conflict of interest}

The authors declare that there is no conflict of interest.

\section{Highlights}

1) The current knowledge: CBCT is a selective method for pre-implanting evaluations.

2) What is new here? Identifying the best slice thickness in different areas of the mandible to detect the mandibular canal borders on CBCT 


\section{References}

1. Pria CM, Masood F, Beckerley JM, Carson RE. Study of the inferior alveolar canal and mental foramen on digital panoramic images. The journal of contemporary dental practice. 2011;12(4):26571. [DOI:10.5005/jp-journals-10024-1045]

2. Angel JS, Mincer HH, Chaudhry J, Scarbecz M. Cone-beam computed tomography for analyzing variations in inferior alveolar canal location in adults in relation to age and sex. Journal of forensic sciences. 2011;56(1):216-9. [DOI:10.1111/j.1556-4029.2010.01508.x]

3. Levine MH, Goddard AL, Dodson TB. Inferior alveolar nerve canal position: a clinical and radiographic study. Journal of oral and maxillofacial surgery : official journal of the American Association of Oral and Maxillofacial Surgeons. 2007;65(3):470-4. [DOI:10.1016/j.joms.2006.05.056]

4. Oliveira-Santos C, Capelozza AL, Dezzoti MS, Fischer CM, Poleti ML, Rubira-Bullen IR. Visibility of the mandibular canal on CBCT crosssectional images. Journal of applied oral science : revista FOB. 2011;19(3):240-3. [DOI:10.1590/S1678-77572011000300011]

5. Weckx A, Agbaje JO, Sun Y, Jacobs R, Politis C. Visualization techniques of the inferior alveolar nerve (IAN): a narrative review. Surgical and radiologic anatomy : SRA. 2016;38(1):55-63. [DOI:10.1007/s00276-015-1510-z]

6. Garay I, Netto HD, Olate S. Soft tissue calcified in mandibular angle area observed by means of panoramic radiography. International journal of clinical and experimental medicine. 2014;7(1):51-6.

7. Schulze K.W.R MM, Schwanecke U . Automated detection of patient movement during a CBCT scan based on the projection data. Oral Surgery, Oral Medicine, Oral Pathology and Oral Radiology.

2015;119(4):468-72.

[DOI:10.1016/j.0000.2014.12.008]
8. Venkatesh E, Elluru S.V. Cone beam computed tomography: basics and applications in dentistry. Journal of Istanbul University Faculty of Dentistry. 2017;51(3 Suppl 1):S102-s121. [DOI:10.17096/jiufd.00289]

9. Ghaeminia H, Meijer GJ, Soehardi A, Borstlap WA, Mulder J, Berge SJ. Position of the impacted third molar in relation to the mandibular canal. Diagnostic accuracy of cone beam computed tomography compared with panoramic radiography. International journal of oral and maxillofacial surgery. 2009;38(9):964-71. [DOI:10.1016/j.ijom.2009.06.007]

10. Hu KS, Choi DY, Lee WJ, Kim HJ, Jung UW, Kim S. Reliability of two different presurgical preparation methods for implant dentistry based on panoramic radiography and cone-beam computed tomography in cadavers. Journal of periodontal \& implant science. 2012;42(2):39-44. [DOI:10.5051/jpis.2012.42.2.39]

11. do Carmo Oliveira M, Tedesco, T.K., Gimenez, T. et al. Analysis of the frequency of visualization of morphological variations in anatomical bone features in the mandibular interforaminal region through cone-beam computed tomography. Surgical and radiologic anatomy : SRA. 2018;40:1119-31. [DOI:10.1007/s00276-018-2040-2]

12. Miles MS, Parks ET, Eckert GJ, Blanchard SB. Comparative evaluation of mandibular canal visibility on cross-sectional cone-beam CT images: a retrospective study. Dento maxillo facial radiology. 2016;45(2):20150296. [DOI:10.1259/dmfr.20150296]

13. Shokri A, Shakibaei Z, Langaroodi AJ, Safaei M. Evaluation of the mandibular canal visibility on cone-beam computed tomography images of the mandible. The Journal of craniofacial surgery. 2014;25(3):e273-7.

[DOI:10.1097/SCS.0000000000000654]

14. Jung YH, Cho BH. Radiographic evaluation of the course and visibility of the mandibular canal. Imaging science in dentistry. 
2014;44(4):273-8.

\section{[DOI:10.5624/isd.2014.44.4.273]}

15. Singh N, Jaju P, Jaju S, Agarwal R. Detection of anatomical variations in mandible by panoramic radiography. Journal of CranioMaxillary Diseases. 2014;3(2):95. [DOI:10.4103/2278-9588.138221]

16. Pour DG, Arzi B, Shamshiri AR. Assessment of slice thickness effect on visibility of inferior alveolar canal in cone beam computed tomography images. Dental research journal. 2016;13(6):527-31. [DOI:10.4103/17353327.197041]

17. Angelopoulos C, Thomas SL, Hechler S, Parissis N, Hlavacek M. Comparison between digital panoramic radiography and cone-beam computed tomography for the identification of the mandibular canal as part of presurgical dental implant assessment. Journal of oral and maxillofacial surgery : official journal of the American Association of Oral and Maxillofacial Surgeons. 2008;66(10):2130-5. [DOI:10.1016/j.joms.2008.06.021]

18. Suomalainen A, Venta I, Mattila M, Turtola L, Vehmas T, Peltola JS. Reliability of CBCT and other radiographic methods in preoperative evaluation of lower third molars. Oral Surg Oral Med Oral Pathol Oral Radiol Endod. 2010;109(2):276-84.

[DOI:10.1016/j.tripleo.2009.10.021]

\section{How to cite:}

Razavi S.H, Berahmand S, Sarikhani khorami Kh, Kaboodsaz yazdi M, Namiranian N: The evaluation of mandibular canal visibility on cone beam computed tomography (CBCT) images: A cross-sectional study. Jorjani Biomedicine Journal. 2019; 7(3): 56-67. 